\title{
MATERNAL BEHAVIOUR IN THE RABBIT: EVIDENCE FOR AN ENDOCRINE BASIS OF MATERNAL- NEST BUILDING AND ADDITIONAL DATA ON MATERNAL-NEST BUILDING IN THE DUTCH-BELTED RACE
}

\author{
M. X. ZARROW, P. B. SAWIN, SHERMAN ROSS, V. H. DENENBERG, \\ D. GRARY, E. D. WILSON AND A. FAROOQ \\ Department of Biological Sciences, Purdue University, Lafayette, \\ Indiana and Roscoe B. Jackson Memorial Laboratory, \\ Hamilton Station, Bar Harbor, Maine, U.S.A.
}

(Received 21st October 1960)

\begin{abstract}
Summary. Two types of nest building are found in the rabbit. One type of nest is made of straw or similar elements available to the animal, and a second type of nest is composed of straw into which hair is incorporated after being plucked from the body. The second type of nest is called a maternal nest and is considered to be part of the maternal behaviour complex. Maternal-nest building was induced in 209 out of $250(84 \%)$ rabbits following complete removal of the entire conceptus mass on Days 20 to 27 of gestation, as compared with a $96 \%$ maternalnest-building rate in 941 control rabbits from the same colony. The maternal-nest-building behaviour was also induced in twelve out of sixteen $(75 \%)$ rabbits following ovariectomy on Days 20 to 24 of gestation and in five out of eleven rabbits made pseudopregnant with human chorionic gonadotrophin (HGG). Comparable results were obtained in a separate study that used the Dutch-belted rabbit, although a higher percentage of animals in this race built maternal nests following pseudopregnancy or ovariectomy during gestation. Treatment with stilboestrol, progesterone and prolactin induced maternal-nest building in four out of seventeen rabbits and lactation in all the animals. Possible endocrine mechanisms involved are discussed.
\end{abstract}

\section{INTRODUCTION}

Maternal behaviour and broodiness have been described in a number of species and attempts made to delineate the various components of this phenomenon and the underlying mechanisms. In general, certain aspects of maternal behaviour have been shown to be under hormonal control in such widely divergent species as the rat (Kinder, 1927; Riddle, Lahr \& Bates, 1935), domestic fowl (Riddle, Bates \& Lahr, 1935) and ring dove (Lehrman, 1959). 
One aspect of maternal behaviour readily studied in the rabbit is that of nest building. The non-pregnant rabbit builds a nest composed of straw or other available substances of a similar nature and this has been called a straw nest. The pregnant rabbit, however, builds a nest composed of straw or other available material of a similar nature into which the animal incorporates hair plucked from its own body (Sawin \& Curran, 1952; Sawin, Denenberg, Ross, Hafter \& Zarrow, 1960). This has been called a maternal nest and appears normally only during pregnancy and to a limited extent during pseudopregnancy (Zarrow, Sawin, Ross \& Denenberg, 1961). This phenomenon is easily observable, being the most striking aspect of maternal behaviour, and can be used in studies of the causative factors of maternal behaviour generally. The present investigation is concerned with this phenomenon as related to or influenced by race, pseudopregnancy, and such procedures as castration, Caesarian section and hormone treatment.

\section{MATERIAL AND METHODS}

All Caesarian sections were carried out under aseptic techniques following Nembutal anaesthesia. The rabbits were palpated prior to the operation and the presence of one or more living foetuses in utero confirmed. The uteri were exposed through a mid-line incision and the conceptus removed through a small incision in the uterus directly over the foetus by the application of a small amount of pressure. No ties were necessary since all bleeding was adequately controlled by the temporary application of a haemostat. In general, it was not necessary to sew the uterine incision except for a few limited instances. In these cases, the incision was closed with several No. 000 catgut sutures. The abdomen was closed in two separate layers (i.e. the muscle with catgut and the skin with surgical silk) and the animal was given 300,000 units of penicillin G intramuscularly. Following removal of foetuses and prior to closure of the abdominal incision, the numbers of corpora lutea and large follicles were noted and recorded.

In general, the same procedure as outlined above was used in the castration experiments. The uteri were exposed through a ventral mid-line incision, the number of foetuses determined and then the ovaries were excised with the use of a cold cautery. Postoperative care was the same for both groups of animals and consisted of a treatment with penicillin and maintenance in a warm room overnight.

Rabbits were made pseudopregnant with human chorionic gonadotrophin (HCG). A dose of 2000 i.u. was injected intravenously on two consecutive days and the animal laparotomized on the 3rd day. The presence of corpora haemorrhagica was taken as post facto evidence that ovulation had occurred and that pseudopregnancy would ensue.

In the experiment involving the treatment of rabbits with the steroid hormones and prolactin, the stilboestrol and progesterone were dissolved in peanut oil and injected daily in a total volume of $0.1 \mathrm{ml}$ via the intramuscular route. The hind legs were used as the sites of injection of the respective hormones. Prolactin was dissolved in distilled water and injected subcutaneously in the 
neck region. All of the experiments reported in this study with one exception were performed on several inbred races of the Jackson Laboratory rabbits. The work discussed under confirmatory experiments was carried out on a single race of Dutch-belted rabbits at Purdue University.

\section{RESULTS}

\section{CAESARIAN SECTION}

It is apparent that removal of the entire conceptus mass precipitates nest building. Table 1 summarizes the frequency with which does from different races built nests following Caesarian section carried out on Days 20 to 27 of gestation. Because of the small frequencies or blanks in a number of the cells, an over-all statistical analysis is not meaningful. However, the data for races III, IIIc, X, and AcEp for Days 20 to 22 were subjected to analyses since

\section{TABLE 1}

FREQUENGY OF NEST BUILDING IN DIFFERENT RACES OF RABBITS FOLLOWING TOTAL GAESARIAN OPERATION ON DAYS 20 TO 27 OF GESTATION

\begin{tabular}{|c|c|c|c|c|c|c|}
\hline \multirow[t]{2}{*}{ Race } & \multicolumn{6}{|c|}{ Length of pregnancy at time of Caesarian section (days) } \\
\hline & 20 & 21 & 22 & 23 & 24 & 27 \\
\hline III & $15 / 18^{*}$ & $23 / 29$ & $7 / 9$ & $7 / 7$ & $0 / 3$ & $11 / 16$ \\
\hline IIIc & $11 / 18$ & $4 / 7$ & $5 / 9$ & $1 / 4$ & & \\
\hline & $8 / 8$ & $24 / 25$ & $1 / 1$ & & & \\
\hline AcEp & $2 / 2$ & $12 / 14$ & $0 / 1$ & & & \\
\hline III $\times X$ & $1 / 1$ & $18 / 19$ & & & & \\
\hline $\mathrm{X} \times \mathrm{III}$ & $18 / 18$ & $9 / 9$ & & & & \\
\hline & $2 / 2$ & $12 / 15$ & $11 / 12$ & $2 / 2$ & & \\
\hline & $3 / 4$ & $4 / 4$ & & & & \\
\hline $\begin{array}{l}\text { Ac } \\
\text { Misc. }\end{array}$ & $1 / 1$ & $\begin{array}{l}3 / 3 \\
5 / 8\end{array}$ & & & & \\
\hline
\end{tabular}

* The numerator of the ratio is the number of does that built nests. The denominator is the total number of does observed.

adequate numbers were available and these races are the ones we have studied and reported on in previous work (Sawin \& Crary, 1953; Ross, Denenberg, Sawin \& Meyer, 1956; Denenberg, Sawin, Frommer \& Ross, 1958; Denenberg, Petropolus, Sawin \& Ross, 1959; Ross, Denenberg, Frommer \& Sawin, 1959). To determine whether these four races differed in the frequency with which nests were built following the Caesarian operation, the frequencies for Days 20 to 22 were combined for each race to give one value (e.g. for Race III the ratio is $45: 56)$. The percentages of does building nests for each of the four races are: III, 80.36; IIIc, 58.82; X, 97.06; and AcEp, 82.35. Chi-square was found to be 15.43 , which is significant beyond the 0.01 level. Thus, it may be concluded that there are significant racial differences in the percentage of does that will build nests following Caesarian section. Race IIIc has the smallest percentage, while Race $\mathbf{X}$ has the highest.

To determine whether the gestation age was important, the data of these four 
races were recombined and grouped by age for Days 20 to 22 . The age of operation and percentage of does building nests are: Day 20, 78.26\%; Day 21, $84.00 \%$, and Day 22, 65.00\%. Chi-square was found to be 3.56 which is not significant. Therefore, within this limited age range the percentage of does building nests does not change significantly.

The data were also analyzed for mean time of nest building for those does that built nests. The number of cases upon which these means are based are the numbers listed in the numerators in Table 1. The statistical analysis was restricted to Race III since this was the only group of sufficient size. The mean time of nest building following Caesarian section for all races is presented in Table 2. It may be seen that Race III does, operated on Day 20, built their

TABLE 2

MEAN TIME OF NEST BUILDING IN DAYS FOLLOWING CAESARIAN SECTION FOR DOES THAT BUILT NESTS

\begin{tabular}{|c|c|c|c|c|c|c|}
\hline \multirow[t]{2}{*}{ Race } & \multicolumn{6}{|c|}{$\begin{array}{l}\text { Time in days after Caesarian section for nest building in rabbits operated on the } \\
\text { following days of gestation }\end{array}$} \\
\hline & 20 & 21 & 22 & 23 & 24 & 27 \\
\hline \multirow{9}{*}{$\begin{array}{l}\text { III } \\
\text { IIIc } \\
X \\
\text { AcEp } \\
\text { III } \times X \\
\text { X } \times \text { III } \\
\mathrm{Da} \\
\text { Os } \\
\text { Ac } \\
\text { Misc. }\end{array}$} & 3.33 & $3 \cdot 22$ & 2.57 & $2 \cdot 57$ & * & $2 \cdot 00$ \\
\hline & 3.91 & 5.00 & $4 \cdot 20$ & 3.00 & & \\
\hline & 3.37 & $3 \cdot 00$ & 2.00 & & & \\
\hline & 3.00 & $3 \cdot 25$ & $*$ & & & \\
\hline & 3.00 & $2 \cdot 44$ & & & & \\
\hline & $2 \cdot 83$ & $2 \cdot 56$ & & & & \\
\hline & 2.00 & 2.50 & $2 \cdot 55$ & $2 \cdot 50$ & & \\
\hline & 3.00 & $\begin{array}{l}2 \cdot 50 \\
3.00\end{array}$ & & & & \\
\hline & 3.00 & $2 \cdot 80$ & & & & \\
\hline
\end{tabular}

nests 3.33 days later, while those operated on Day 27 built nests 2.00 days later. These data were subjected to an analysis of variance to determine whether the time of nest building varied as a function of length of gestation. An F ratio of 3.49 was obtained (d.f. $=4,58$ ), which is significant beyond the 0.05 level. This finding indicates that following the Caesarian section the lapsed time for nest building to occur decreases as the gestation age increases. Inspection of the data for the other races in Table 2 tends to support this finding. There are some reversals to the general picture but in the majority of cases it can be seen that earlier nest building is correlated with later gestation age.

In order to determine whether the occurrence of nest building following Caesarian section was related to characteristics of the ovary or conceptus mass, nest builders and non-nest builders from Races III and IIIc were compared on the following indices: number of corpora lutea, follicles, live and dead foetuses found at the time of operation, and various ratios of the above. The data were restricted to animals that had the Caesarian section on Days 20 to 23 of gestation. Table 3 summarizes the findings. No significant differences were found on any of the measures between those rabbits that did build nests and those that failed to do so in either of the races. Therefore, it seems unlikely that the 
number and viability of foetuses or other ovarian indices are related to the mechanisms that bring about nest building.

\section{NATURE OF RACE DIFFERENCES}

Since the nest builders and non-nest builders did not differ, these two subgroups were pooled and comparisons were made between the four major races as shown in Table 4. Analyses of variance yielded significant differences beyond the 0.01 level among races for number of corpora lutea, number of live foetuses

TABLE 3

COMPARISON OF GERTAIN OVARIAN AND CONGEPTUS INDICES FOR NEST BUILDERS AND NON-NEST BUILDERS FOLLOWING CAESARIAN SEGTION ON DAYS 20 TO 23 OF GESTATION IN RAGES III AND IIIC

\begin{tabular}{|c|c|c|c|c|}
\hline & \multicolumn{2}{|c|}{ Race III } & \multicolumn{2}{|c|}{ Race $I I I c$} \\
\hline & $\begin{array}{c}\text { Nest } \\
\mathcal{N}^{*}=46\end{array}$ & $\begin{array}{l}\mathcal{N} o \text { Nest } \\
\mathcal{N}=9\end{array}$ & $\begin{array}{c}\text { Nest } \\
\mathcal{N}=18\end{array}$ & $\begin{array}{l}\text { No Nest } \\
\mathcal{N}=14\end{array}$ \\
\hline $\begin{array}{l}\text { Corpora lutea } \\
\text { Live foetuses } \\
\text { Dead foetuses } \\
\text { Large follicles }\end{array}$ & $\begin{array}{r}12 \cdot 17 \\
5 \cdot 70 \\
2 \cdot 13 \\
17 \cdot 17\end{array}$ & $\begin{array}{r}11 \cdot 11 \\
3 \cdot 78 \\
1 \cdot 22 \\
16 \cdot 67\end{array}$ & $\begin{array}{r}11 \cdot 44 \\
4 \cdot 89 \\
1 \cdot 94 \\
16 \cdot 22\end{array}$ & $\begin{array}{r}11 \cdot 93 \\
4 \cdot 29 \\
2 \cdot 36 \\
16 \cdot 07\end{array}$ \\
\hline$\frac{\text { Corpora lutea }}{\text { Large follicles }}$ & 0.79 & $0 \cdot 70$ & 0.84 & $0 \cdot 88$ \\
\hline$\frac{\text { Corpora lutea }}{\text { Live foetuses }}$ & 3.57 & $3 \cdot 37$ & $2 \cdot 96$ & $2 \cdot 92$ \\
\hline$\frac{\text { Corpora lutea }}{\text { Dead foetuses }}$ & $4 \cdot 79$ & $5 \cdot 07$ & 4.09 & $3 \cdot 58$ \\
\hline$\frac{\text { Corpora lutea }}{\text { Total foetuses }}$ & $2 \cdot 06$ & $2 \cdot 65$ & $2 \cdot 81$ & $2 \cdot 45$ \\
\hline
\end{tabular}

* Number of rabbits.

and number of large follicles. Further analyses determined this racial difference to be more specifically between the large-sized races (III and IIIc) and the small-sized races ( $\mathrm{X}$ and $\mathrm{AcE}$ ) whereas the differences within the large or small groups were not significant, suggesting that these differences are directly related to the general size of the animal.

In attempting to further differentiate the relation of these effects to each other, it was found that the ratio of corpora lutea to number of dead foetuses was significant at the 0.05 level. However, since this difference is found only between Race III and Races AcEp and X and the other three ratio measures do not differ significantly, regardless of size of animal, the meaning of this one significant ratio is doubtful. Further, whereas the analysis of corpora lutea revealed significant differences, while the analysis of number of dead foetuses failed to do so, the significant difference found in this ratio measure probably is due directly to the corpora lutea data.

In summary, although the ovarian and conceptus comparisons do show racial differences, they were found to be unrelated to the phenomenon of nest building, thus suggesting aetiologically independent mechanisms. The significant 
differences in number of corpora lutea, number of live foetuses, and number of large follicles can be directly attributed to the general size of the animal whereas nest-building differences seem to be independent.

\section{TABLE 4}

OVARIAN AND CONGEPTUS COMPARISONS FOR FOUR RACES OF RABBITS FOLLOWING GAESARIAN SECTION ON DAYS 20 TO 23 OF GESTATION

\begin{tabular}{|c|c|c|c|c|c|}
\hline & $\begin{array}{c}\text { Race III } \\
\mathcal{N}^{*}=55\end{array}$ & $\begin{array}{c}\text { Race IIIc } \\
\mathcal{N}=32\end{array}$ & $\begin{array}{c}\text { Race } X \\
\mathcal{N}=24\end{array}$ & $\begin{array}{c}\text { Race AcEp } \\
\mathcal{N}=16\end{array}$ & $P$ \\
\hline $\begin{array}{l}\text { Corpora lutea } \\
\text { Live foetuses } \\
\text { Dead foetuses } \\
\text { Large follicles }\end{array}$ & $\begin{array}{r}12 \cdot 00 \\
5 \cdot 38 \\
1 \cdot 98 \\
17 \cdot 09\end{array}$ & $\begin{array}{r}11 \cdot 66 \\
4 \cdot 62 \\
2 \cdot 12 \\
16 \cdot 16\end{array}$ & $\begin{array}{r}8 \cdot 00 \\
2 \cdot 83 \\
1 \cdot 75 \\
10 \cdot 79\end{array}$ & $\begin{array}{r}7 \cdot 37 \\
4 \cdot 06 \\
0 \cdot 81 \\
10 \cdot 37\end{array}$ & $\begin{array}{l}0.01 \\
0.01 \\
\text { N.s. } \dagger \\
0.01\end{array}$ \\
\hline$\frac{\text { Corpora lutea }}{\text { Large follicles }}$ & 0.78 & 0.85 & $0 \cdot 80$ & 0.81 & N.s. \\
\hline$\frac{\text { Corpora lutea }}{\text { Live foetuses }}$ & 3.54 & 2.94 & $2 \cdot 37$ & $2 \cdot 06$ & N.s. \\
\hline$\frac{\text { Corpora lutea }}{\text { Dead foetuses }}$ & 4.84 & 3.87 & $2 \cdot 63$ & $2 \cdot 06$ & 0.05 \\
\hline$\frac{\text { Corpora lutea }}{\text { Total foetuses }}$ & $2 \cdot 16$ & $2 \cdot 65$ & $2 \cdot 33$ & 1.40 & N.s. \\
\hline
\end{tabular}

* Number of rabbits in each group.

+ Not significant.

\section{CASTRATION DURING PREgNANCY}

A total of sixteen miscellaneous rabbits was castrated during the 21st to 24th day of gestation. All animals aborted, but only twelve of the sixteen, or $75 \%$, pulled hair from their body and built maternal nests. In all instances where careful observations were possible, the animals aborted first and built the nests shortly thereafter. Although the percentage of animals building nests was lower than in both the control and Caesarian experiments, it should be kept in mind that the animals were not selected from any specific race. Actually, some of the animals tended to show a poor reproductive index prior to the experiment. Hence it is not too surprising that the number of successful nest builders was somewhat low.

\section{GAESARIAN SEGTION AND IMPLANTATION OF PARAFFIN RODS}

The entire conceptus mass was removed on the 23rd to 25th day of pregnancy and two or three paraffin rods were inserted into the lumen of each uterine horn to simulate the presence of the conceptus and maintain uterine distention (Zarrow, Wilson, Caldwell, Yochim \& Sawin, 1960). In addition, the uterine horns were tied at the cervical end to prevent expulsion of the rods. Six of the eight rabbits $(75 \%)$ treated as above built maternal nests within 3 days after the operation. It is apparent that the maintenance of uterine distention failed to interfere with maternal-nest building. 


\section{PSEUDOPREGNANCY}

Eleven pseudopregnant rabbits were observed daily for 30 days and the time of maternal-nest building recorded. Only five of the eleven rabbits, or $45 \%$, built maternal nests. However, in all five instances the nests were built between the 17 th and the 19th day of pseudopregnancy, i.e. at the end of the pseudopregnancy period.

Daily observations throughout the period of pseudopregnancy and in the following experiment revealed a new facet to the nest-building pattern of the rabbit. All of the eleven does built nests composed of the available straw, but only four of these subsequently pulled hair and incorporated it into the nest. The fifth rabbit built the straw nest and hair nest almost simultaneously, i.e., within hours of each other.

\section{HORMONE TREATMENT}

A total of seventeen rabbits of highly mixed genetic origin were treated with hormone preparations in order to determine whether maternal-nest building could be induced in this manner. Only females were used and in a few instances the animals were castrated. The treatment was designed along the pattern suggested by Meites \& Sgouris (1954) for the induction of lactation. The rabbits were injected with $10 \mu \mathrm{g}$ of stilboestrol and $1 \mathrm{mg}$ of progesterone or $10 \mu \mathrm{g}$ of stilboestrol and $2 \mathrm{mg}$ of progesterone for 14 days. This was followed with 200 i.u. of prolactin for 5 to 7 days. In all instances, full development of the mammary glands was obtained and milk could be expressed from the nipples. Eleven of the seventeen does built straw nests in the course of the treatment with the steroid hormones and four of the seventeen or $22 \%$, incorporated hair into the nests, i.e. built maternal nests.

In a second experiment, an attempt was made to precipitate maternal-nest building in five pregnant rabbits prior to the predicted time for such behaviour by treatment with 200 i.u. of prolactin twice daily for eight days starting on the 20 th day of gestation. Premature nest building failed to occur in any of the treated animals.

\section{GONFIRMATORY EXPERIMENTS WITH THE DUTGH-BELTED STRAIN}

A series of experiments comparable to those described above were also carried out with a Dutch-belted race of rabbits. This race of rabbits is well known for a high fertility rate and for this reason were added to the various strains being studied for maternal behaviour. Thus far, maternal-nest building has been obtained in fifty-three out of fifty-four, or $98 \%$, of the normal pregnancies studied. Analysis of the time of nest building indicates that this is essentially a partum-nest-building race since $9.4 \%$ built maternal nests a day or more prior to parturition; $81.2 \%$ built nests on the day of parturition, and $7.5 \%$ built nests shortly after delivery of the young.

Studies on the effect of pseudopregnancy, castration during pregnancy and Caesarian section indicate a high degree of nest building in each instance (Table 5). Eight-five per cent of the pseudopregnant rabbits built maternal 
nests. Castration during late pregnancy (21 to 24 days of gestation) and Caesarian section (20 to 27 days of gestation) resulted in nest building in $100 \%$ for the former and $80 \%$ for the latter. It should be emphasized that nest building following the above procedures was premature, i.e. it occurred within 1 to 3 days after the operation and significantly sooner than if gestation had been allowed to proceed normally.

\section{TABLE 5}

MATERNAL-NEST BUILDING IN THE RABBIT FOLLOWING ENDOCRINE MANIPULATION

\begin{tabular}{|c|c|c|c|}
\hline \multirow[b]{2}{*}{ Treatment } & \multirow{2}{*}{$\begin{array}{l}\text { No. } \\
\text { rabbits }\end{array}$} & \multicolumn{2}{|c|}{ Maternal nest } \\
\hline & & $\begin{array}{l}\text { Total } \\
\text { No. }\end{array}$ & $\%$ \\
\hline
\end{tabular}

Compilation of all available races at Jackson Laboratory

\begin{tabular}{l|r|r|r}
\hline Controls & 941 & 901 & 96 \\
Caesarian* & 250 & 209 & 84 \\
Castration during pregnancy† & 16 & 12 & 75 \\
Pseudopregnancy & 11 & 5 & 45 \\
Stilboestrol, progesterone, prolactin & 17 & 4 & 22 \\
\hline
\end{tabular}

Dutch-belted race at Purdue University

\begin{tabular}{l|r|r|r}
\hline & 54 & 53 & 98 \\
Controls & 20 & 17 & 85 \\
Pseudopregnancy & 5 & 4 & 80 \\
Castration during pregnancyt & 5 & 5 & 100 \\
\hline
\end{tabular}

* Total conceptus mass removed on Days 20 to 27 of gestation. + Ovaries removed on Days 21 to 24 of gestation.

\section{DISGUSSION}

The present study presents evidence for the possible involvement of the endocrine system in one aspect of maternal behaviour, nest building. As an end point, the 'maternal nest' is especially useful since it has been shown in other species to have an endocrine component, particularly in birds. In mammals, it seems to be peculiar to a few species of lagomorphs (Cahalane, 1947) of which the domestic rabbit is the best known. In the case of the rabbit, the maternal nest appears to be a development arising from the tendency for burrowing which is common to both sexes and results first in the straw nest, which is later lined with fur. The lion has also been reported to pluck hair following parturition although it has been suggested that hair pulling in this instance is concerned with making the nipples available for nursing the young (J. B. Cooper, personal communication, 1959).

The evidence for endocrine control of this phenomenon for the rabbit is not complete although it is strongly suggested by the data (Table 5 ). The initial 
observations of Sawin \& Curran (1952) described and quantified the pheno. menon of nest building during pregnancy. Prior to this time, Tietz (1933) had already suggested the presence of a humoral mechanism since nest building and hair plucking were noted during pseudopregnancy.

In general, the rabbit first tends to build a straw nest and then, prior to or at parturition, lines the nest with hair plucked from its own body. The time lag between the straw construction and the incorporation of hair may vary from nil (both occurring simultaneously), to a period of hours or days, and as the data indicate, the phenomenon frequently occurs at the end of pseudopregnancy, in which case ovulation has occurred but either implantation has failed, or, if successful, has been followed by death and resorption of foetuses. The data for this is overwheIming (Tietz, 1933; Sawin \& Crary, 1953; Deutsch, 1957). In addition, maternal-nest building can be precipitated by removal of the conceptus mass or by castration on Days 20 to 27 of gestation and possibly later. In the latter instance, nest building was preceded by abortion. Similarly, maternal-nest building was obtained in a small percentage of non-pregnant rabbits treated with stilboestrol, progesterone, and prolactin. This treatment produced lactation in all animals but nest building in only a few, although Denenberg et al. (1958) reported a high correlation between lactation and nest building. Chang (1951) also reported a failure on the part of the rabbits to build maternal nests under the conditions of his experiment although good lactation was present. Similarly, Robson (1937) failed to get nest building in rabbits hypophysectomized during the latter part of pregnancy and treated with progesterone and prolactin. From these results, it seems probable that lactation and maternal-nest building are two separate events correlated in time but not with a common mechanism. If they are associated with the same mechanism, the stimulus required for nest building must be very much stronger than that for lactation.

Analyses in two strains of pregnant rabbits relating ovarian and conceptus indices with nest building failed to reveal any useful correlations with the occurrence or non-occurrence of this phenomenon. It is possible that more than the pituitary-ovarian interaction is involved in this phenomenon since Chu (1944) failed to obtain nest building in pregnant, thyroidectomized rabbits.

It is very obvious that a likely explanation of the onset of maternal-nest building following abortion or Caesarian section is the hormonal upset following the termination of gestation. However, since the nest is built just prior to parturition in a normal pregnancy, it is impossible to explain both instances on the basis of hormonal changes following termination of pregnancy. Nevertheless, it has been recently demonstrated that the progestogen-oestrogen ratio is reversed in the rabbits several days before parturition, and that the progestogen dominance seen throughout the major portion of pregnancy is reversed to an oestrogen dominance several days prior to delivery (Schofield, 1957). Hence, a change in hormonal balance does occur in both instances of maternal-nest building and the same explanation can account for the nest building seen after Caesarian section, pseudopregnancy and normal pregnancy. The limited data from the experiment on treatment with hormones and the above consideration would tend to indicate that the hormones involved are oestradiol, progesterone 
and possibly prolactin. The possibility that maternal-nest building is due to a decrease in uterine distention following Caesarian section or abortion due to castration is not acceptable since the maintenance of uterine distention with paraffin rods failed to prevent maternal-nest building.

The cumulative evidence indicates the involvement of an endocrine factor or factors in maternal-nest building but no hypothesis can be definitely established, at this time to account for both the maternal-nest building that (1) normally occurs prior to or on the day of parturition or (2) is experimentally induced following removal of the conceptus mass. It would appear that an endocrine imbalance or change in the concentration of plasma hormones may be involved in both instances, since uterine distention can be ruled out.

\section{ACKNOWLEDGMENTS}

Aided in part by Research Grants RG 5228, RG 5229 and RG 6263 from the Division of Research Grants and MY 1604 from the National Institute of Mental Health, National Institutes of Health, U.S. Public Health Service.

The chorionic gonadotrophin $\left(\mathrm{APL}^{\mathrm{R}}\right)$ was obtained through the courtesy of Ayerst Laboratories. Progesterone was obtained through the courtesy of Schering Corporation. Prolactin was obtained through the courtesy of $\operatorname{Dr} \mathrm{A}$. Borman, Squibb Institute for Medical Research, New Jersey.

\section{REFERENCES}

Cahalane, V. H. (1947) Mammals of North America. Macmillan, New York.

ChANG, M. C. (1951) Maintenance of pregnancy in intact rabbits in the absence of corpora lutea. Endocrinology, 48, 17.

CHU, N. P. (1944) The influence of the thyroid on pregnancy and parturition in the rabbit. F. Endocrin. 4, 109.

Denenberg, V. H., Petropolus, S. F., Sawin, P. B. \& Ross, S. (1959) Genetic, physiological, and behavioral background of reproduction in the rabbit: VI. Maternal behavior with reference to scattered and cannibalized newborn and mortality. Behaviour, 15, 71.

Denengerg, V. H., Sawin, P. B., Frommer, G. P. \& Ross, S. (1958) Genetic, physiological, and behavioral background of reproduction in the rabbit: IV. An analysis of maternal behavior at successive parturitions. Behaviour, 13, 131.

Deutsch, J. A. (1957) Nest building behaviour of domestic rabbits under semi-natural conditions. Brit. 7. Anim. Behav. 5, 53.

Kinder, E. F. (1927) A study of nest building activity of the albino rat. F. exp. Zool. 47, 117.

Lehrman, D. (1959) On the origin of the reproductive behavior cycle in doves. Trans. N.Y. Acad. Sci. 21, 682 .

Meites, J. \& Sgouris, J. T. (1954) Effects of altering the balance between prolactin and ovarian hormones on the initiation of lactation in rabbits. Endocrinology, 55, 530.

Riddle, O., Bates, R. W. \& Lahr, E. L. (1935) Prolactin induces broodiness in fowl. Amer. J. Physiol. $11,352$.

Riddle, O., LAHR, E. L. \& BATES, R. W. (1935) Maternal behavior induced in virgin rats by prolactin. Proc. Soc. exp. Biol., N.Y. 32, 730.

Rosson, J. M. (1937) Maintenance of pregnancy and of the luteal function in the hypophysectomized rabbit. F. Physiol. 90, 145.

Ross, S., Denenberg, V. H., Frommer, G. P. \& Sawin, P. B. (1959) Genetic physiological and, behavioral background of reproduction in the rabbit. V. Nonretrieving of neonates. F. Mammal. 40, 91 .

Ross, S., Denenberg, V. H., Sawin, P. B. \& Meyer, P. (1956) Changes in nest building behaviour in multiparous rabbits. Brit. 7. Anim. Behav. 4, 69.

Sawin, P. B. \& Crary, D. D. (1953) Genetic and physiological background of reproduction in the rabbit. II. Some racial differences in the pattern of maternal behavior. Behaviour, 6, 128. 
SAwin, P. B. \& Gurran, R. H. (1952) Genetic and physiological background of reproduction in the rabbit. I. The problem and its biological significance. F. exp. Zool. 120, 165.

Sawin, P. B., Denenberg, V. H., Ross, S. Hafter, E., \& Zarrow, M. X. (1960) Maternal behavior in the rabbit: hair loosening during gestation. Amer. F. Physiol. 198, 1099.

Schofield, B. M. (1957) The hormonal control of myometrial function during pregnancy. F. Physiol. 138, 1 .

TIETz, E. G. (1933) The humoral excitation of the nesting instincts in rabbits. Science, 78, 316.

Zarrow, M. X., SAwin, P. B., Ross, S. \& Denenberg, V. H. (1961) Maternal behaviour in the rabbit and a consideration of its endocrine basis. Roots of Behavior. Ed. E. L. Bliss. Hoeber, New York.

Zarrow, M. X., Wirson, E. D., Caldwell, Jr., A. L., Yochim, J. \& Sawin, P. B. (1960) Local action. of placental progestogen on uterine musculature of the rabbit. Fertil. $\mathcal{E}$ Steril. 11, 370. 